\title{
Tratados de libre comercio Colombia-Asia: Cuestión preliminar y perfiles de negociación*
}

\author{
Jorge Ricardo Palomares García" \\ Nattaly Calonje Londoño
}

Recibido: 16 de agosto de 2015 - Revisado: 19 noviembre de 2015

Aprobado: 30 de noviembre de 2015

\section{Resumen}

Colombia, en los últimos gobiernos, se ha caracterizado por ser un país que desea proyectarse internacionalmente, a través de mecanismos como las agendas diplomáticas y los tratados de libre comercio. Sin embargo, en materia de libre comercio, el Estado colombiano debe revisar distintas variables, tales como el perfil comercial de cada uno de los nuevos mercados, sus importaciones y exportaciones potenciales, así como las posibles ventajas que puede representar para el mercado colombiano. Por ello, el presente artículo, resultado de investigación, revisa los perfiles comerciales de los países asiáticos que, o bien tienen un tratado de libre comercio con Colombia -en negociación o firmado-, o bien se encuentran en etapa de acercamiento.

Palabras clave: tratados de libre comercio, derecho de la integración colombiana, China, Corea del Sur, Japón.

\footnotetext{
"Artículo resultado del proyecto de investigación "aspectos jurídico-económicos de los tratados de libre comercio celebrados por Colombia con Estados Unidos, la Unión Europea y Asia”, realizado en colaboración con el grupo de investigación Estudios internacionales, de la Fundación Universitaria Los libertadores, y cofinanciado por esta entidad, mediante Acta 027 de 2013.

*A Abogado, magíster en Derecho de la Universität Konstanz; candidato a doctor en Derecho de la Universität Konstanz, Alemania; docente investigador de la Universidad Libre, Seccional Bogotá. Correos electrónicos: jorge.palomares-garcia@hotmail.com, jorger.palomaresg@unilibrebog.edu.co

*- Abogada, magíster en Derecho de la Universität Konstanz; especialista en Derecho Comercial de la Pontificia Universidad Javeriana; miembro de la Cancillería del Ministerio de Relaciones Exteriores y co-investigadora del proyecto de investigación en Derecho Privado, Universidad Católica de Colombia. Correo electrónico: nattaly.calonje@hotmail.com
} 


\title{
Free Trade Agreements Colombia-Asia: preliminary ISSUES AND PROFILES OF NEGOTIATION
}

\begin{abstract}
Under the previous government, Colombia was characterized as a country that sought to project itself internationally through various channels. These channels included but were not limited to diplomatic agendas and free trade agreements. However, in terms of free trade, the new Colombian government should now review different issues, such as the commercial profile of each new market, import and export potential and the possible benefits for the Colombian economy. Therefore, this paper seeks to review the business profiles of Asian countries that have either an existing free trade agreement with Colombia or are in the process of rapprochement. Keywords: Free trade agreements, andean's law, South Corea, China, Japan.

\section{Tratados de livre comércio Colômbia - Ásia QUESTÃo PRELIMINAR E PERFIS DE NEGOCIAÇÃo}

\section{Resumo}

A Colômbia, nos últimos governos, tem se caracterizado por ser um país que deseja se projetar internacionalmente através de mecanismos como as agências diplomáticas e os tratados de livre comércio. Porém, no relacionado com um livre comércio, o Estado colombiano deve revisar distintas variáveis, como o perfil comercial de cada um dos novos mercados, suas importações e exportações potenciais, assim como as possíveis vantagens que podem representar para o mercado colombiano. Por isso, este artigo, resultado de pesquisa, revisa os perfis comerciais dos países asiáticos que, ou já tem um tratado de livre comércio com a Colômbia, - em negociação ou assinado - ou estão em etapa de aproximações.

Palavras-chave: tratados de livre comércio, direito da integração colombiana, China, Coreia do Sul, Japão.

\section{Introducción}

El presente artículo es resultado de la primera fase de investigación titulada Análisis jurídico económico de los tratados de libre comercio entre Colombia, 
Asia, Estados Unidos y la Unión Europea, trabajado realizado en conjunto con investigadores del grupo Derecho y globalización, de la Fundación Universitaria Los Libertadores y bajo la dirección de la profesora Paula Lucía Arévalo Mutiz. El objeto de la primera fase consistió en determinar los elementos jurídicos que soportan la celebración de los tratados de libre comercio entre Colombia y otros actores, así como la estructura normativa de cada tratado que se encontrase en negociación, firma o en vigencia.

Para ello, la investigación se dividió en tres componentes, focalizados en Estados Unidos, la Unión Europea y Asia, en los cuales se revisaron aspectos importantes, como el perfil de cada una de las contrapartes de los tratados de libre comercio, la etapa de negociación, el cuerpo normativo del tratado -en caso de existir- y las posibles ventajas o desventajas que implican dichos tratados.

El método empleado en esta investigación es el Derecho comparado y se compone de dos elementos concretos. El primero de ellos es un ejercicio comparativo normativo, es decir, que la primera actividad consistió en identificar los cuerpos normativos que orientan u orientarían las relaciones de Colombia con cada una de las tres zonas, para determinar cuáles son los aspectos comunes-comparación desde la semejanza-, así como los elementos diferenciadores de cada cuerpo normativo-comparación desde la diferencia-. El segundo es el ejercicio de comparación, pero desde una dimensión de la sociología jurídica. Ello significa, que no basta con comparar los cuerpos normativos, sino que es necesario revisar los intereses del Estado colombiano, de los países parte de las zonas de negociación y los perfiles de cada uno de ellos. Lo anterior permitirá comprender no solo cómo se diseñan ciertas normas, sino también cuáles son los criterios de selección de las contrapartes. Para esto se analizaron los datos realizados por la Organización Mundial de Comercio (por ejemplo el rank in World Trade) y los estudios hechos por diversas instituciones colombianas sobre el perfil económico de cada uno de los estados.

Como resultado, en el componente asiático, se estableció que el Estado colombiano se encuentra, actualmente, en un acercamiento y dos negociaciones. E1 proceso de acercamiento es con la República Popular de China, con la cual se ha firmado carta de intención para la celebración de un tratado de libre comercio; mientras que los procesos de negociación se adelantan actualmente con Japón y Corea del Sur -este ya suscrito, mas no en vigor debido a los debates en la Corte Constitucional-. Esta situación permitió que la investigación, en este componente, se centrase en los perfiles comerciales de cada uno de los estados contrapartes. Sin 
embargo, el estudio determinó que era necesario establecer si dichas negociaciones estaban limitadas, de una u otra forma, por tratados de libre comercio o por normas de derecho comunitario. En concreto se revisó si es posible para el Estado colombiano, celebrar negociaciones comerciales pese a la existencia de obligaciones ante la Comunidad Andina (en adelante CAN).

Por ello, el presente documento se estructura en cuatro partes. La primera consiste en revisar el interrogante del trato preferencial de la Comunidad Andina, a la luz de la jurisprudencia constitucional colombiana (I). Hecho dicho análisis, se procederá a estudiar el perfil de un socio potencial y, actualmente, referente obligatorio, China (II), del cual aún no se tienen perfiles en el Ministerio de Comercio, Industria y Turismo (en adelante MinCIT), para celebrar con él un tratado de libre comercio. Posteriormente se revisarán dos países, de los cuales existen perfiles y negociaciones en curso para celebración de tratados de libre comercio. Dichos países son Japón y Corea del Sur (III). Finalmente, se procederá a realizar algunas conclusiones, hacer una síntesis y plantear algunos interrogantes, los cuales darán continuidad a la investigación.

\section{Cuestión preliminar: la política colombiana de celebración de tratados de libre comercio}

La primera cuestión que debe resolverse, consiste en si Colombia puede celebrar tratados de libre comercio, de forma independiente, pese a su participación en un bloque regional, como lo es la CAN. Dicho interrogante tiene dos contextos particulares. El primero de ellos es que en virtud de este bloque regional, se lograron avances significativos a mediados de los 90 y comienzos del 2000 (Palomares, G., 2011, p. 149) a través de una colaboración activa entre presidentes, especialmente de los Estados de Colombia y Venezuela, que permitieron mejoras de los diseños políticos para el funcionamiento adecuado del mercado andino (Milanese, 2005, p. 101). Asimismo, se crearon nuevos lazos comerciales -entre empresas-, que permitieron un incremento del comercio intra-zona (Palomares G., 2011, p. 149).

$\mathrm{El}$ segundo contexto consiste en la existencia de normas nacionales y supranacionales, que otorgan un trato preferente para los países latinoamericanos. Por una parte, el art. 227 de la Constitución Política de Colombia de 1991 establece que el Estado promoverá la integración económica, social y política con las demás 
naciones y, especialmente, con los países de América Latina y del Caribe (...). Por otra parte, el Acuerdo de Cartagena consagra que las relaciones exteriores, que sean de interés intrarregional, estarán a cargo de la CAN, a través del Consejo Andino de Ministros de Relaciones Exteriores (art. 50 Acuerdo de Cartagena) y, en caso de ser el Estado quien individualmente adelante acercamientos -especialmente sobre temas consagrados en el Acuerdo de Cartagena-, lo logrado en dichos acercamientos será favorable para los demás estados miembros de la CAN, conforme al art. 139 inc. 1 del Acuerdo de Cartagena. Por ello podría decirse que, en cierta medida, la exploración de posibles socios comerciales está supeditada a las normas de la CAN.

Sin embargo, la jurisprudencia de la Corte Constitucional influyó en la no continuidad -avanzada- de las exportaciones entre Colombia y Venezuela, en la intra-zona. Dicha influencia, se vio en la interpretación que ha dado la Corte Constitucional en relación con la prioridad que tiene el proceso de integración andino sobre otros procesos, especialmente con países que no corresponden a Latinoamérica y el Caribe. Ejemplo de ello es la Sentencia de Constitucionalidad C-864 de 2006, en la cual la Corte Constitucional se cuestionó, entre otros, sobre la participación de Colombia en escenarios que no corresponden al proceso de integración andino. Para la Corte Constitucional, debe tenerse en cuenta que, conforme a los arts. 226 y 227 de la Constitución Política, existen distintos tipos de Integración (C-864 de 2006): a) los simples acuerdos bilaterales; b) los acuerdos de integración -como el G3 y la CAN- y; c) los acuerdos de complementación económica, suscritos en virtud de la ALADI.

Entre estas modalidades de integración, la Corte Constitucional encuentra que la Constitución faculta al Estado Colombiano, bien sea a negociar con estados latinoamericanos, conforme a los arts. 9 y 227 de la Constitución Política, o bien a negociar con otros estados, conforme los arts. 226 y 227 de la misma. La Corte Constitucional no encuentra, entre las distintas modalidades, una prevalencia especial, es decir, que todas ellas gozan del mismo valor, pues permiten la realización de los fines propuestos por la Constitución Política.

Sin embargo, es de anotar que la Corte Constitucional, en el estudio de prevalencias, omite los apartados de los arts. 9 y 227 de la Constitución Política, que consagran un trato preferencial para los países de América Latina y del Caribe, como un sustento normativo para dar prioridad al Bloque Regional Andino y sus reglas de integración, especialmente en lo concerniente a las negociaciones comerciales en bloque, pues, en palabras de la Corte Constitucional: 
Esto no significa que una dirección contraria en el manejo de las relaciones internacionales, como ocurriría en el caso en que se privilegie los acuerdos económicos con otras naciones del mundo distintas a las que integran la región de América Latina sean per se inconstitucionales, pues lo que la Carta Fundamental establece, a juicio de esta Corporación, es un mandato de preferencia en la orientación de las relaciones internacionales y no una camisa de fuerza en el desarrollo de las mismas (C-864 de 2006).

El efecto práctico de esta consideración por parte de la Corte Constitucional se manifiesta en: a) las excesivas negociaciones bilaterales que tiene actualmente el Estado colombiano y; b) la búsqueda de nuevos socios comerciales, entre ellos los asiáticos. Ello se evidencia en los lineamientos del MinCIT para la celebración de tratados de libre comercio. En el estudio del caso Corea del Sur, el MinCIT (2012) manifestó que:

El Acuerdo comercial con Corea del Sur obedece a un esfuerzo que de tiempo atrás adelanta el país para lograr acceso preferencial en diferentes mercados para los productos y servicios colombianos, así como al objetivo de estrechar lazos comerciales con los países asiáticos y atraer inversión productiva de los mismos. En este sentido, se busca la diversificación de destinos para nuestras: actualmente solamente el $5 \%$ de nuestras exportaciones de bienes se dirigen al Asia-Pacífico. Entretanto Chile exporta el $34 \%$, y Perú el $22 \%$ de sus exportaciones hacia dicho destino. En parte estas cifras obedecen a la baja vocación exportadora de Colombia: mientras Colombia exporta tan solo el $14.4 \%$ de su Producto Interno Bruto, Perú exporta el $21.2 \%$ y Chile el $32.8 \%$ del total de su PIB. Colombia podrá aprovechar las ventajas que puede representar el estrechar relaciones económicas con Corea, y en general con los países asiáticos que para el año 2040 representarán el 66 \% del PIB mundial (p. 30).

Lo anterior supone, que en Colombia existen varios sectores para los cuales es importante estrechar las relaciones comerciales con países asiáticos, pues de esta manera se generan flujos considerables de importaciones y dinamismo en las exportaciones (Reina; Salamanca; Forero, 2009, pp. 43 ss.).

En virtud de dicha facultad de celebrar tratados internacionales de libre comercio, sin la aparente obligación de trato preferente hacia la Comunidad Andina, se 
procederá a estudiar cada uno de los perfiles en los cuales el Estado colombiano ha considerado al continente asiático.

\section{El acercamiento comercial a China}

\section{A. Contextos determinantes de China}

Uno de los principales actores, proyectado por Colombia, en las relaciones comerciales internacionales es China. El 11 de mayo del 2015, la ministra de Relaciones Exteriores, María Ángela Holguín Cuéllar y el embajador de China en Colombia, Wang Xiaoyan, suscribieron el Acuerdo de Cooperación Económica y Técnica entre el Gobierno de la República de Colombia y el Gobierno de la República Popular China. A través de este convenio, el Gobierno de China realiza una donación de 50 millones de yuanes con el fin de ejecutar proyectos para fortalecer los procesos que llevan a cabo las entidades del orden nacional (http:// www.cancilleria.gov.co/newsroom/news/colombia-y-china-suscribieron-conveniocooperacion-economica-y-tecnica, 2015).

Lo anterior supone que optar por este país no constituye, por parte del Estado colombiano, una decisión aleatoria o un simple efecto natural de la política de expansión de escenarios comerciales, sino que, por el contrario, corresponde a la conjunción de distintos factores, determinantes no solo para Colombia, sino para el mercado global. La literatura ha agrupado dichos factores en tres categorías: a) los cambios políticos en China; b) la transformación de las relaciones internacionales y; c) la economía, proyectada tanto nacional como internacionalmente.

\section{a. Cambios políticos en China}

Bajo la categoría política, la literatura ha sostenido que, a partir de la consolidación de la República Popular China, a mediados de 1949, los modelos gubernamentales tuvieron dos orientaciones. El primer modelo, que podría entenderse como la primera generación de la República Popular China y dirigido por Mao Zedong (Posada, 2011, p. 120), se caracterizó por la búsqueda de una transición hacia un sistema moderno, basado en la estatalización de los medios de producción y un modelo socialista de planeación económica central (Posada, 2011, p. 120). En este punto, Mao Zedong apoyó a la Unión Soviética y se fue en contra de Estados 
Unidos y el mundo capitalista (Delage, 2003, p. 68). Sin embargo dicho modelo, enfocado en un modelo socialista, no trajo consigo resultados positivos para la República Popular China, por el contrario, incluso después de la denominada revolución cultural (Ferreiro, S., 2010, p. 12) implicó problemas como el estancamiento de la producción, hiperpolitización y agudización del conflicto social (Ferreiro, S., 2010, p. 12). El segundo modelo liderado por Deng Xiaoping a partir de 1976 y denominado como la segunda generación (Leiteritz, 2012, p. 54), se caracterizó por una reorientación del modelo socialista, del Estado y la economía (Leiteritz, 2012, p. 54). Dicha reorientación, (Bustamante, 2002, p. 63) fundada en la necesidad de abrir a China hacia lo internacional - the outsider world- (Leiteritz, 2012, p. 54), se concretó en cuatro políticas: agricultura, ciencia y tecnología, defensa e industria (Ferreiro, 2010, p. 14), las cuales contenían ciertos elementos liberales.

En el siglo XX, la República Popular China tenía como objetivo superar la "humillación" causada por las guerras del Opio y las amenazas externas, que según el país, fueron las responsables de su decaimiento y subordinación frente a otras potencias. Líderes chinos como Sun Yatsen, Chiang Kai-shek Deng Xiaoping y Jiang, han convenido que la República Popular China debe ocupar una posición de igualdad frente a las otras potencias, es decir, debe estar completamente integrada (Delage, 2003, p. 69). Para lograrlo, debe integrarse no solo con países desarrollados como Estados Unidos, sino que también debe estrechar relaciones con países del Tercer Mundo, incluyendo países latinoamericanos (Shixue, 2006, p. 66).

\section{b. La transformación de las relaciones internacionales}

En cuanto a las relaciones internacionales, pareciese que, con el cambio del régimen de Mao Tse Tung al de Deng Xiaoping, en la República Popular China las relaciones internacionales se tornasen en un objeto de investigación, que permite la identificación de China como un actor con características propias o diferenciadoras. Ejemplo de ello, es el estudio realizado por Yaqing sobre la evolución de la teoría de las relaciones internacionales en la República Popular China (2013).

En dicha investigación, Yaqing demostró que China, a partir de 1978, cruzó por tres etapas de asunción y desarrollo de una teoría de las relaciones internacionales (Yaqing, 2013, p. 69). La primera fase, denominada como pre-teórica de las relaciones internacionales, se caracterizó por el empleo de la teoría marxista para comprender las relaciones internacionales - con poca investigación académica al 
respecto- (Yaqing, 2013, p. 70), la cual trató de resolver el dilema entre una China hermética o abierta a las relaciones internacionales (Yaqing, 2013, p. 70), mediante la discusión de dos posturas teóricas. La primera, orientada en los análisis de Lenin, sostenía la existencia de una lucha de clases internacional (Yaqing, 2013, p. 70); mientras que la segunda, que enfatizaba en la prioridad que goza el bienestar de la nación, sostenía la necesidad de realizar reformas y generar desarrollo económico en la República Popular China (Yaqing, 2013, p. 70).

La segunda etapa, caracterizada por el regreso de académicos chinos formados en universidades norteamericanas (Cueva, 2009, p. 148) y traducciones de obras clásicas de las relaciones internacionales (Yaqing, 2013, p. 73), se denominó como fase teórica y se orientó por el debate entre las tradiciones realista y liberal respecto del papel de China en la sociedad global. Mientras que la teoría realista sostenía que la República Popular China debía orientarse, en materia de relaciones internacionales, hacia la consolidación de un poder material y una seguridad territorial (Yaqing, 2013, p. 71), la teoría liberal optaba por una participación china en el contexto internacional, bajo los criterios de cooperación internacional y la integración progresiva en la sociedad internacional (Yaqing, 2013, p. 71).

No obstante, debido a la fuerte influencia de las teorías norteamericanas -especialmente el constructivismo- (Yaqing, 2013, pp. 75 ss.) así como el acenso pacífico de la República Popular China, las teorías de las relaciones internacionales se encauzaron hacia la comprensión de un modelo chino, cuya prioridad es la participación económica en el contexto internacional. Es decir, el perfil internacional y la percepción del mundo sobre la República Popular China, ha sido reformado recientemente gracias a que cada vez es mayor su poder económico, por lo que "ha logrado un mayor activismo diplomático en su política hacia otros países” (Delage, 2003, p. 67).

\section{c. La economía}

Tanto el cambio de modelo político, como la orientación hacia las relaciones internacionales trajeron consigo, como tercera categoría, una dimensión económica. La República Popular China, bajo el gobierno de Deng Xiaoping, realizó un conjunto de reformas económicas estructurales, que implicaron una resignificación del Estado chino en el contexto internacional. La primera medida consistió en la implementación de la gradualidad (Ferreiro, 2010, p. 24), la cual se materializó en tres acciones concretas: a) la creación de Zonas Económicas Especiales (Ferreiro, 2010, p. 24), en las cuales se implementaban instrumentos capitalistas, a fin de 
observar su comportamiento y, en caso de resultados positivos, se ampliaban las mismas; b) el mantenimiento del sistema dual, es decir, que la economía planificada operaba pero, una vez la producción superaba las metas fijadas a la empresa, esta podía comercializar el excedente libremente, tanto en precios como en compradores (Ferreiro, 2010, p. 24) y; c) el sostenimiento financiero de empresas públicas y privadas durante la fase de aprendizaje, apoyado por un alto ahorro, que fue administrado por el sistema bancario estatal (Ferreiro, 2010, p. 24).

La segunda medida consistió en constituirse como un escenario favorable para la inversión extranjera. Ello implicó, por una parte, en el otorgamiento de garantías estatales para la inversión extranjera (Ferreiro, 2010, p. 25), tales como la reducción del grado de incertidumbre, incentivos para los inversores extranjeros, mano de obra barata (Rosales; Kuwajama, 2007, p. 88) y la baja sindicalización. Por otra parte, la República Popular China debió asumir medidas para poder ingresar a la Organización Mundial de Comercio -OMC-, logro que se alcanzó solo hasta el 2001 (Posada, 2011, p. 105). Sin embargo, las medidas más importantes para la República Popular China son, desde su incorporación en la OMC, el reconocimiento del Estado como una economía de mercado (Borda; Paz, 2012, p. 96). Si bien China tiene socios comerciales en África (Alden, 2012, pp. 22 ss.) y Latinoamérica, como Argentina (Nacht, 2012, pp. 110ss.), varios de los posibles socios potenciales, que podría implicar un incremento en las condiciones económicas de la República China -por ej. la Unión Europea, Estados Unidos, Japón, India y Australia (Borda; Paz, 2012, p. 97), no han reconocido al Estado chino como una economía de mercado. Ello se debe a que la República Popular China es el Estado con mayor investigaciones antidumping, así como con mayores sanciones por dichas investigaciones (Borda; Paz, 2012, p. 96).

La tercera medida consiste en el fomento del ahorro, a través del incremento del ahorro estatal, con bajas tasas de interés y sin competencia interna, así como el control riguroso de compra de vivienda (Ferreiro, 2010, p. 26). Junto a esta medida, la República Popular China ha implementado otras dos. La primera de ellas consiste en la propiedad exclusiva estatal del suelo, es decir, que si bien pueden existir concesiones a empresas, la propiedad de suelo es del Estado (Ferreiro, 2010, p. 26). La segunda de ellas consiste en la participación del Estado chino en las empresas extranjeras, a través de la compra de acciones, lo que hace que el Estado pueda estar en todas partes (Ferreiro, 2010, p. 26) y controlar las actividades económicas. 


\section{B. Situación de China en virtud del cambio de modelo}

La implementación progresiva de medidas, orientadas a cambiar el comportamiento económico chino en el contexto internacional -sin desconocer sus raíces culturales y políticas- ha traído consigo resultados que posicionan a la República Popular China como uno de los actores más influyentes en el mercado internacional (Alden, 2012, p. 21). Ello se ve reflejado en varios hechos.

Por una parte, la República Popular China, desde una dimensión interna, ha logrado durante los últimos treinta años un incremento constante de su producto interno bruto cercano a los dos puntos (Rosales; Kuwayana, 2012, p. 15). Por otra parte, desde una dimensión externa, la República Popular China se ha convertido en el segundo país con mayores reservas (Nacht, 2012, p. 110), al poseer cerca de dos punto seis (2.6) billones de dólares (Rosales; Kuwayana, 2012: p. 23). Asimismo, debido a las bajas tasas de interés, el Estado Chino se constituye, en la actualidad, como el principal acreedor de los Estados Unidos (Rosales; Kuwayana., 2012, p. 23), pues tiene en su poder nueve punto siete billones (9.7) de dólares en títulos estadounidenses a corto y mediano plazo (Rosales; Kawayana, 2012, p. 24).

Tanto el crecimiento estable como la cantidad considerable de reservas, le ha permitido a la República Popular China pensar en nuevos escenarios, en los cuales sería el Estado Chino, o sus empresas, un inversor extranjero o el demandante de determinados productos. Por ejemplo, actualmente la economía china ve en los países latinoamericanos la ejecución de iniciativas de inversión en las áreas de infraestructura y recursos naturales (Rosales; Kawayana, 2012, p. 27), así como en la inversión de productos como la soja (Nacht, 2012, p. 115). Igualmente, China ha buscado en países africanos la inversión en petróleo, minerales estratégicos y otros (Alden, 2012, p. 23). Estas relaciones, a su vez, se sustentan en una promoción del yuan como moneda no solo de intercambio, sino también de reserva internacional (Rosales; Kawayana, 2012, p. 27). Ejemplo de ello es el acuerdo de currency swap firmado por la Argentina y la República Popular China, en el cual se consagró un intercambio recíproco por setenta mil millones de yuanes, para que el gobierno argentino pudiese pagar las importaciones chinas con esta moneda (Rosales; Kawayana, 2012, p. 27). Sin embargo, la consideración del yuan como moneda de reserva internacional no es considerada por la literatura como una meta de próximo alcance, pues se requiere que el gobierno chino desarrolle un sistema financiero más eficaz y elimine los controles sobre el tipo de cambio y la cuenta de capitales (Rosales; Kawayana, 2012, p. 27). 
Junto a los aspectos de crecimiento económico y de inversión, la República Popular China ha tenido un posicionamiento interesante en materia de importaciones y exportaciones. De acuerdo al perfil estadístico de la OMC (2014), que mide el comportamiento del mercado chino durante el periodo 2010-2012, ha ocupado los primeros puestos en el rank in World trade 2012, respecto a las importaciones y exportaciones -sin contar las operaciones en la Unión Europea-.

Asimismo, de acuerdo al estudio de Rosales y Kawayana (2014, p. 23), la alta producción de bienes a bajos costos, ha permitido que en los países destinatarios de las exportaciones se presente una demanda elevada de esos bienes, pero sin ocasionar una inflación que afecte los niveles de ahorro y manteniendo bajas tasas de interés.

\section{Los riesgos del crecimiento chino}

Pese al crecimiento significativo de la economía china, algunos autores plantean ciertas dudas respecto al funcionamiento de su mercado y, de acuerdo a ellas, enuncian los retos que deben ser asumidos por la República Popular China. Ejemplo de ello es la reflexión hecha por Cueva, quien sostiene que China deberá enfrentarse a tres desafíos (2009, p. 149).

El primer reto consiste en el modelo depredador del mercado chino (Cueva, 2009, p. 149). El crecimiento de la República Popular China no solo se determina por la cantidad de exportaciones e importaciones, sino por el consumo que realizan sus habitantes y empresas. En los últimos años, el crecimiento constante implica que el consumo ha incrementado en aspectos energéticos y alimenticios, por lo que se requiere de una provisión mayor de energía, minerales y otros productos (Alden, 2012, p. 23). Ello se ve reflejado en el hecho de la transición de la economía china, a partir del 2003, de autosuficiencia energética hasta constituirse en el segundo consumidor de energía, así el hecho del incremento de la demanda en materias primas -de las cuales era el principal exportador-y de cereal (Cueva, 2009, p. 149). Ello ha significado que la República Popular China busque desde Angola hasta Sudán reservas petroleras, así como concesiones mineras en la República Popular del Congo (Alden, 2012, p. 24), mientras que en Argentina explora cultivos estratégicos de soja (Nacht, 2012, pp. 115 ss.).

El segundo reto consiste en la relación entre la República Popular China con Estados Unidos, la cual se asemeja, según Cueva, a una relación de "dos borrachos sosteniéndose mutuamente” (Cueva, 2009, p. 149). Ello se debe a que, la 
alta producción de bienes con mano de obra barata, así como la alta compra de títulos del Estado, implica un riesgo en los mercados laborales norteamericanos y europeos (Cueva, 2009, p. 150), y adicionalmente, una depreciación peligrosa del dólar (Cueva, 2009, p. 150). De alguna manera, Estados Unidos ve a China como un rival, pues le preocupa ser desplazado por las negociaciones que tiene América Latina con China, sin embargo, este es solo un nuevo socio más, de los muchos que ya tiene América latina, pues su objetivo principal, es atraer inversión extranjera y estimular el crecimiento liberalizando el mercado (Shixue, 2006, p. 76).

$\mathrm{El}$ tercer riesgo consiste en las políticas laborales, que no solo tengan presente la eliminación progresiva de la pobreza -como lo ha logrado China en los últimos años-, sino que logren disminuir las brechas de desigualdad entre la población (Cueva, 2009, p. 151). Dichos factores, tanto positivos como negativos, deberían ser objeto de estudio por parte del Estado colombiano, para verificar las ventajas que proporcionan estos acuerdos.

Shixue señala que tanto China como América Latina deben solucionar algunos problemas, dentro de los que señala la distancia geográfica existente entre las partes. No solo en relación con la distancia existente entre ambos, sino por las diferencias culturales y las barreras lingüísticas especialmente, que llevan a un desconocimiento de los países, y genera incertidumbre en los productores y pequeños empresarios latinoamericanos (2006, p. 76).

\section{Acercamiento a otros países asiáticos: el caso de Japón y Corea del Sur}

\section{A. Las relaciones con Japón y su perfil comercial internacional}

A diferencia de la República Popular China, Japón cuenta con una trayectoria mayor en el ámbito de las relaciones internacionales. Ejemplo de ello, son las aproximaciones comerciales que ha tenido este Estado con Colombia desde comienzos de 1900 (Orbes, 1998, p. 146). Asimismo, Colombia se encuentra actualmente, en el proceso de negociación de un tratado de libre comercio con el Estado nipón (MinCIT, 2014). Ello permite analizar dos contextos concretos del Estado asiático: el primero de ellos es el perfil general comercial de Japón, así como su estrategia de actuación comercial en las relaciones comerciales; el segundo definido por Colombia, en el cual se establecen los potenciales mercados que tienen uno y otro. 
Desde su perfil general, Japón es un Estado que, de acuerdo a las estadísticas y a los datos ofrecidos por la OMC, tiende a un crecimiento estable. Ello se refleja, por una parte, en el crecimiento uniforme y constante del flujo de importaciones y exportaciones de Japón. Durante el periodo 2005-2009, el Estado nipón incrementó su volumen de exportaciones en Latinoamérica en un 34,8 \%, al pasar de veintitrés mil trescientos veintiún millones ochocientos noventa y cinco mil dólares (\$23.321`895.000.oo), a treinta y un mil cuatrocientos cuarenta millones ciento veintinueve mil dólares (31.440’129.000.oo), de acuerdo al estudio de la CEPAL (2010, p. 154). Por otra parte, Japón se ha consolidado como uno de los mayores donantes en Latinoamérica (CEPAL, 2010, p. 26), y en implementar, dentro de sus pilares de la política exterior económica, la acción de cooperación. Ejemplo de ello es el esfuerzo del Estado nipón por promover la interacción entre inversión, comercio y la asistencia oficial para el desarrollo (AOD), esfuerzo caracterizado por el énfasis en el mejoramiento de la infraestructura y la formación en recursos humanos, a fin de promover el comercio y las inversiones en el país receptor, así como de revitalizar el sector productivo (CEPAL, 2010, p. 26).

Estos dos aspectos se complementan con el empleo de la estrategia sogo-shosha (CEPAL, 2010, p. 27), fundada en el modelo Thrid-Country-Trade (Orbes, 1998, p. 150). La sogo-shosha se entiende como la estrategia de alianza público-privada mediante la cual, el sector privado japonés concentra sus inversiones en recursos -naturales y energéticos-, así como en infraestructura y seguridad alimentaria (CEPAL, 2010, p. 27), mientras que el sector público japonés dispone la utilización de herramientas de asesoría y asistencia de carácter público y privado, para ayudar a las empresas japonesas inversoras (CEPAL, 2010, p. 27), e igualmente la asistencia financiera al sector privado japonés y de seguros para actividades comerciales en el exterior (CEPAL, 2010, p. 27). Esta alianza se orienta bajo el modelo teórico del Third-Country-Trade, el cual consiste en la conjunción de tres variables (Orbes, 1998, p. 150): el país origen del producto; el país que hace de intermediario y; el país destino de la exportación. Dicha conjunción puede ofrecer dos alternativas. La primera de ellas consiste en que una empresa japonesa, quien hace las veces de intermediario, establece contacto entre una empresa nacional, quien produce un bien u ofrece un servicio, con otra empresa japonesa que requiere de dicho bien o servicio (Orbes, 1998, p. 150), todo ello a cambio de una comisión. El segundo modelo, consiste en vender los bienes o servicios a la empresa japonesa intermediaria, quien se encargaría de su comercialización en Japón; sin embargo, el despacho 
físico se encontraría en el país productor, de tal forma que la mercancía permanece con el sello del país de origen (Orbes, 1998, p. 151).

Las descripciones señaladas anteriormente, no distan del perfil diseñado por el Estado colombiano. De acuerdo a los datos del MinCIT, Japón es un país que se caracteriza porque:

Durante el 2012, [tuvo] un crecimiento del $2 \%$ del PIB, una recuperación con respecto al año anterior, soportada por la construcción de la infraestructura afectada por el terremoto, el tsunami y el desastre nuclear del 2011; se espera que para 2013 caiga a 1,3\% debido a las constantes presiones deflacionarias. El comercio seguirá lento el resto del año debido a la débil demanda de exportaciones de Europa y Estados Unidos. Con respecto a los precios, se espera una caída promedio anual de $0.4 \%$ para el 2013 (...) (MinCIT, 2012).

La estabilidad económica de Japón, así como su recuperación, se debe de acuerdo a los estudios hechos por la Subdirección de política industrial y comercial del departamento nacional de planeación, al impulso del sector servicios. Según la subdirección (2012):

En Japón el sector servicios es el que más aporta al PIB y al empleo, seguido de las industrias manufactureras las cuales se encuentren ampliamente diversificadas. Entre los principales sectores de servicios se encuentran los servicios comunales, sociales y personales; comercio, reparación, restaurantes y hoteles; actividades inmobiliarias; y transporte, almacenamiento y comunicaciones. En la industria manufacturera de Japón se destacan sectores como el automovilístico, la electrónica, tecnologías de la información, maquinaria de precisión y acero por ser muy competitivas y activas en exportaciones e inversiones en el exterior. El sector agrícola está altamente protegido y aporta marginalmente al PIB y al empleo, ya que aproximadamente solo el $15 \%$ de la superficie de Japón es apta para el cultivo (p. 32).

De este perfil, el Estado colombiano formuló dos interrogantes. El primero de ellos consistió en cuáles son los bienes y servicios que, potencialmente, pueden ser exportados hacia Japón y el, cuáles podrían ser importados desde Japón. Frente al primer interrogante, el Estado colombiano identificó como bienes fundamentales, 
todos aquellos relacionados con productos agrícolas, minerales y materias primas (Bermúdez; Álvarez, 2012, p. 20). Ellos son (MinCIT, 2012): a) café y sus derivados -cascarillas, extractos, esencias- así como té o yerba mate; b) óxidos de manganeso; c) coques y semicoques de hulla, lignito, briquetas, ovoides y combustibles similares; d) piedras preciosas -excepto diamantes- o semipreciosas, naturales o trabajadas; e) bananos y plátanos, frescos o secos; f) peces vivos, entre otros productos.

Respecto al segundo interrogante, los productos que podrían ser importados desde Japón son bienes manufacturados, así como tecnología o de apoyo industrial. A modo ilustrativo, se pueden enunciar los siguientes (MinCIT, 2012): automóviles de turismo y demás vehículos automotores destinados a transporte de personas; neumáticos; vehículos automotores para transporte de mercancías; instrumentos y aparatos de medicina, cirugías, odontología o veterinaria, entre otros.

Vale la pena señalar que, aunque las exportaciones e importaciones colombianas han aumentado progresivamente, el comercio entre Colombia y Japón ha estado algo estancado en las últimas décadas, lo que sugiere, que aún existe una buena oportunidad para profundizar el comercio entre los dos países (Bermúdez; Álvarez, 2012, p. 20). En este sentido, como se mencionó, las exportaciones colombianas tienen cabida sobre todo en productos agrícolas y agroindustriales, especialmente en siete sectores: producción agrícola, producción pecuaria, elaboración de frutas (legumbres, hortalizas, aceites y grasas), producción de panadería, producción de café, ingenios (refinería de azúcar y trapiches), y otros productos alimenticios ${ }^{1}$.

Asimismo, Japón tiene una gran oportunidad con nueve productos, que ya han ingresado a otros mercados latinoamericanos. Estos son: fibras sintéticas y artificiales, productos de caucho, vidrio y productos de vidrio, maquinaria de uso general, vehículos, automotores y sus motores, maquinaria de uso especial, aparatos e instrumentos médicos (exc. instrum. ópticas), industrias básicas hierro y acero, sustancias químicas básicas (Reina; García, 2008, p. 18).

Respecto a la inversión extranjera, el grupo de estudio conjunto para un acuerdo de asociación económica entre Colombia y Japón (2012), con el propósito de consolidar un ambiente adecuado de inversión, las empresas japonesas realizaron inversiones en Colombia de aproximadamente dos mil millones de dólares (USD 2.000`000.000.oo), especialmente a través de industrias manufactureras, automóviles, motocicletas y ascensores (Grupo de estudio conjunto, 2012, p. 9). De

${ }^{1}$ Países como Brasil, México y Chile ya han tomado la delantera en el mercado japonés, excepto en el caso del café (Reina; García, 2008, p. 18) 
acuerdo con dicho estudio, Japón podría incrementar las oportunidades de inversión en Colombia, en virtud del Acuerdo para Promoción y Protección Recíproca de Inversiones (Grupo de estudio conjunto, 2012, p. 9).

Según estos criterios, y en resumen, Colombia tendría oportunidades interesantes en materia comercial con Japón. Dicha conclusión la sostiene también Fedesarrollo, para quién:

En los últimos años se han presentado mejoras sustanciales en las condiciones para hacer negocios en Colombia. De acuerdo con el reporte Doing Business del Banco Mundial, Colombia fue el país de América Latina que más subió en el ranking de facilidad para hacer negocios. (...) Colombia es hoy en día el segundo mejor país para hacer negocios en América Latina después de Chile, y también revela que en el último año subió 13 puestos en el escalafón.

Vale la pena destacar algunos de los indicadores más importantes de Colombia en cuanto a su entorno para los negocios. En el índice de Protección de inversores Colombia ocupa el segundo lugar en América Latina después de Perú (Reina; García, 2008, p. 9).

De acuerdo con Fedesarrollo, entre los años 2007 y 2008, la inversión en Colombia ha tenido un crecimiento cerca de tres veces más que el PIB, configurándose como el motor más dinámico del crecimiento económico. Adicionalmente, el segundo impulsador más dinámico del crecimiento, ha sido la exportación, esta ha aumentado por encima del PIB entre 2006 y 2008, aunque con un desarrollo menor que la inversión. Lo anterior propugna para que haya una armonía entre las fuentes de dinamismo internas y externas, lo que implica una ventaja de $\mathrm{Co}^{-}$ lombia, frente a otros países latinoamericanos, quienes son más propensos a la crisis internacional, pues su desempeño ha estado muy ligado a sus exportaciones (Reina; García, 2008, p. 4).

\section{B. Las relaciones con Corea del Sur y su perfil comercial}

El tercer Estado asiático, con el cual Colombia busca establecer alianzas comerciales, es Corea del Sur, y aunque la crisis económica reciente, incidió negativamente en el ritmo del crecimiento económico coreano y colombiano, pues a pesar de que entre el año 2000 y 2007 ambos países registraron tasas de crecimiento de 4,8 \%, 
entre el año 2008 y 2009, hubo una desaceleración, ninguno de estos dos países, registró tasas negativas en este periodo (Bermúdez; Álvarez, 2010, p. 2).

El 21 de febrero del año 2013, se firmó un Acuerdo de libre comercio con Corea del Sur, el primero que Colombia firma con un país del continente asiático y que actualmente se encuentra pendiente de refrendación por parte del Congreso colombiano (http://www.cecolomboasiatico.com/tlc-s/corea, 2015) El MinCIT sostuvo que la necesidad de celebrar un tratado de libre comercio con este Estado se debe a:

Un esfuerzo que de tiempo atrás adelanta el país para lograr acceso preferencial en diferentes mercados para los productos y servicios colombianos, así como al objetivo de estrechar lazos comerciales con los países asiáticos y atraer inversión productiva de los mismos. En este sentido, se busca la diversificación de destinos para nuestras (MinCIT, 2011, p. 1).

De manera análoga, Fedesarrollo señala que la:

República de Corea se convierte en una puerta de entrada a esta región -Asia- no solo por el dinamismo de su economía sino porque recientemente ha estrechado los lazos con algunos de sus países vecinos por medio de la firma del TLC con Asia y un Acuerdo de Asociación Económica (EEA) con India. Además de las estrechas relaciones que sostiene con otros mercados como China y Japón (Reina; Salamanca; Forero, 2009, pp. 43 ss.).

Desde una perspectiva general, Corea del Sur, de acuerdo con los datos recolectados por el Estado colombiano, tiene unas condiciones económicas favorables para Colombia y visceversa. Según Fedesarrollo, es conveniente para ambos países desarrollar relaciones comerciales, pues tienen interés en ingresar a los mercados regionales, de los que ya hace parte el otro país (Reina; Salamanca; Forero, 2009, p. 66). De acuerdo al MinCIT, Corea del Sur se caracteriza por (MinCIT, 2011, p. 2): a) tener cuarenta y ocho millones de habitantes y un PIB per cápita de USD $\$ 27.700 ` 000.000$.oo; b) séptimo exportador y quinto importador mundial de bienes; c) noveno exportador y quinto importador de servicios y; d) constituirse actualmente en un inversionista clave, especialmente para Latinoamérica. Dentro de 
Latinoamérica, Colombia ocupa el quinto lugar en materia de inversión proveniente de Corea del Sur. Según los datos de ProExport (2010, p. 10)

Colombia ocupa el quinto lugar de Latinoamérica como destino de inversión con un $4 \%$ de participación y una inversión de US $\$ 309,8$ millones, principalmente en la comercialización de vehículos (Hyundai) y componentes electrónicos (LG) además de un proyecto en el sector de comunicaciones (Skyzen).

En cuanto a las posibilidades de importación y exportación, el mercado surcoreano no dista demasiado del japonés, salvo en algunos productos específicos. Según el MinCIT (2013, p. 5), Colombia podría exportar hacia Corea del Sur los siguientes productos, entre otros: café y sus derivados; desperdicios y desechos de cobre; insecticidas, raticidas, fungicidas, herbicidas, entre otros; desperdicios y desechos -chatarra-, de fundición, hierro o acero; cueros y pieles y; chocolate y demás preparaciones derivadas el cacao. Por otra parte, los productos que pueden ser importados son, entre otros (MinCIT, 2013, p. 5): polímero de etileno en formas primarias; máquinas para lavar ropa, incluso con dispositivo de secado; armamento militar y municiones; máquinas y aparatos para acondicionamiento de aire y; máquinas y aparatos de oficina.

En este sentido, se puede hablar entonces, de una complementariedad de las canastas exportadoras e importadoras de estos dos países, pues mientras que Corea del Sur es exportador de bienes de media y alta tecnología, Colombia exporta bienes primarios y bienes provenientes de recursos naturales. En relación con las importaciones, Corea del Sur, importa bienes primarios y los provenientes de recursos naturales, mientras que Colombia, importa bienes de media y alta tecnología (Bermúdez; Álvarez, 2010, p. 3,4).

En cuanto a los efectos económicos que podría traer el tratado de libre comercio entre Colombia y Corea del Sur, el Estado colombiano solo hizo una previsión de los efectos positivos del mismo, más no un cálculo de los posibles riesgos que puede asumir la economía colombiana con la apertura a este nuevo socio comercial. Según el MinCIT (2011):

De acuerdo con análisis de FEDESARROLLO existen opciones concretas en el ámbito comercial y de inversión que resaltan la importancia de concretar el tratado 
de libre comercio. El estudio hace evidente que existen sectores en los que Colombia ha demostrado tener una ventaja comparativa revelada, en los cuales algunos países latinoamericanos han logrado penetrar el mercado coreano y los exportadores colombianos aún no.

Al estimar el impacto económico de un TLC entre Colombia y la República de Corea por medio del Modelo de Equilibrio General de Fedesarrollo, se estima que el PIB real a precios de mercado se incrementaría en un poco más de $0,5 \%$ como resultado de la entrada en vigencia del TLC con la República de Corea. El resultado positivo sobre la producción nacional se explica por el incremento en el consumo privado, que se elevaría en 0,82 \% y el aumento en $0,22 \%$ del valor de las exportaciones colombianas. Por su parte, las importaciones totales colombianas prácticamente no tendrían variación, lo que revela que la mayor parte del aumento de las compras desde Corea se daría a costa de una desviación de comercio de otros orígenes (pp. 7 ss.).

\section{Conclusiones y cuestiones}

El estudio realizado, permitió al equipo de investigación llegar a las siguientes conclusiones:

1. Si es posible para el Estado colombiano celebrar negociaciones comerciales, con países diferentes a los miembros de la CAN, pese a la existencia de obligaciones con esta Comunidad.

2. Debido a que existen varios tipos de integración (C-864 de 2006), y que de acuerdo a la Corte Constitucional, no hay una prevalencia especial entre ellos, es perfectamente válido realizar acuerdos con países no miembros de la CAN, pues estas negociaciones permiten la realización de los fines propuestos por la Constitución Política.

3. Optar por la República Popular de China como socio, no fue una decisión aleatoria o un simple efecto natural de la política de expansión de los escenarios comerciales para Colombia, por el contrario, corresponde a la conjunción de distintos factores, determinantes no solo para Colombia, sino para el mercado global.

4. Un gran problema para el relacionamiento de Colombia y de países asiáticos es la distancia geográfica existente entre las partes. Asimismo, las diferencias 
culturales y, especialmente, las barreras lingüísticas llevan a un desconocimiento de los países y genera incertidumbre en los productores y pequeños empresarios latinoamericanos.

5. En cuanto a Japón, la duda se refleja en cuáles son los bienes y servicios que, potencialmente, pueden ser exportados hacia Japón y cuáles podrían ser importados desde Japón. No obstante, se puede deducir que las canastas de Colombia y Corea del Sur se complementan en la medida en que Corea del Sur es exportador de bienes de media y alta tecnologías, Colombia exporta bienes primarios y bienes provenientes de recursos naturales.

6. Un gran problema de la cooperación que se ha realizado entre Colombia y varios de los países asiáticos, es que no se ha profundizado mucho en las desventajas que representa la misma.

7. Una ventaja de Colombia, frente a otros países latinoamericanos, es que estos son más propensos a la crisis internacional, pues su desempeño ha estado muy ligado a sus exportaciones, lo que no sucede para Colombia.

8. La República de Corea se convierte en una puerta de entrada a Asia, no solo por el dinamismo de su economía sino porque recientemente ha estrechado los lazos con algunos de sus países vecinos por medio de la firma del TLC con Asia y un Acuerdo de Asociación Económica (EEA) con India.

9. Existe complementariedad de las canastas exportadoras e importadoras de Corea del Sur, quién es exportador de bienes de media y alta tecnologías, y Colombia quien exporta bienes primarios y bienes provenientes de recursos naturales.

En materia comercial, en síntesis y de acuerdo a la jurisprudencia de la Corte constitucional, pareciese que el Estado colombiano está facultado para buscar, a fin de garantizar un crecimiento económico, nuevos mercados bajo las reglas de la reciprocidad y del derecho internacional económico. Ello ha permitido que Colombia busque en países asiáticos nuevas posibilidades, no solo de exportación, sino también de inversión e importación, para ofrecer alternativas a las empresas colombianas, así como para lograr el ingreso de productos al mercado colombiano. No obstante, debe tenerse en cuenta, que aunque negociar con países del continente asiático resulta en muchos sentidos beneficioso para Colombia, las negociaciones con Colombia, son también positivas para estos países, que buscan estrategias de 
crecimiento para posicionarse a nivel internacional, lo que con países como Colombia, significa disminución del riesgo.

En ese intento, surgen algunos interrogantes interesantes para el derecho colombiano. El primero de ellos consiste en la no previsión de riesgos inherentes a la apertura a nuevos socios comerciales. Cada uno de los perfiles estudiados presenta ventajas competitivas significativas en materia comercial, que podrían condicionar las negociaciones. Por ejemplo, los tres estados estudiados gozan de una mayor solidez y estabilidad económica que Colombia. Cada uno de ellos se caracteriza por una industria más organizada y con mayor oferta que la colombiana mientras que la colombiana no goza de dichos avances. Ello puede verse en los productos que puede ofrecer el Estado colombiano, ante los productos que ofrecen los estados asiáticos.

De esta situación surgen dos riesgos. El primero de ellos consiste en si el Estado colombiano cuenta con medidas para proteger las empresas dedicadas a actividades industriales desarrolladas también por los estados asiáticos. El segundo consiste en si esta ventaja comparativa puede afectar los términos en los cuales Colombia puede negociar, especialmente si se tiene en cuenta que China es, actualmente, una potencia económica -como se vio en el documento-, mientras que Japón y Corea del Sur son actores significativos en el comercio global. Siendo así, Colombia debe hacer un análisis sobre las limitaciones que tiene en cuanto a su capacidad productiva, esto para constatar qué productos con valor agregado puede exportar a los países asiáticos, de tal manera que pueda mejorar su competitividad a nivel regional y mundial (Wise, 2012, p 180). Wise indica que un posible problema, es que países como China, a diferencia de Estados Unidos, no va a ejercer presión para que se diseñen e implementen reglas y normas que promuevan la competitividad en los países de América Latina (Wise, 2012, p 185).

El segundo interrogante que nace del análisis preliminar en torno a la relación con la Comunidad Andina, consiste en la posible violación de la obligación de no discriminación. Como resultado de lo ocurrido con el tratado de libre comercio con Estados Unidos, Colombia se obligará a eliminar ciertas barreras regladas por el ordenamiento jurídico. Dicha eliminación, que ha sido objeto de discusión en la Comunidad Andina desde 1999, trae consigo el interrogante de si los derechos creados por los nuevos tratados de libre comercio favorecerán también a los Estados miembros de la Comunidad Andina o si, por el contrario, solo tendrán unos beneficios parciales y, por tanto, se podrían prever conflictos, incluso judiciales, por la violación del principio de no discriminación. 
El tercer interrogante consiste, aunque más desde una perspectiva del análisis económico del derecho, en sí las decisiones adoptadas respecto a la celebración de tratados de libre comercio son las idóneas para alcanzar metas constitucionales tales como el desarrollo económico, el pleno empleo, o si las mismas realmente pueden crear asimetrías perjudiciales para el Estado colombiano. Dicho interrogante, en especial, requeriría de un análisis a largo plazo y del empleo de unas variables concretas. Sin embargo, estos tres interrogantes nos permiten concluir que una revisión jurídico-económica de los tratados de libre comercio con Asia podría ofrecer herramientas importantes, como la creación de estrategias que sirvan para la adaptación a cada uno de los mercados, de los que Colombia quiere hacer parte. En palabras de Reina y Oviedo (2013), Colombia debe darse la oportunidad de disfrutar, como lo han hecho otro países en la región, de las ventajas que representan las ventas a la región más dinámica del mundo en la actualidad, es decir, Asia (2013, p. 2).

\section{Referencias}

Alden, C. (2012). China and Africa: A distant Mirror of Latin America. Revista Colombia Internacional, 75, 19-47, Colombia: Universidad de los Andes.

Bermúdez, M., y Álvarez, M. (2010). Corea del Sur: Dinámica comercial y relaciones bilaterales con Colombia, Documentos OEE-04. Ministerio de Comercio, Industria y Turismo, Colombia, [en línea] recuperado de http://www.tlc.gov.co/publicaciones.php?id=736.

Bermúdez, M., y Álvarez, M., (2012). Japón y Colombia: una integración necesaria, en Documentos Oficina de Estudios Económico. Ministerio de Comercio, Industria y Turismo, Colombia, pp. 1-30, documento [en línea] recuperado de http://www.tlc. gov.co/publicaciones.php?id=4818.

Borda, S., y Paz, M. (2012). Relaciones bilaterales China y Colombia: 1990-2010, Revista Colombia Internacional, No. 75, Universidad de los Andes, Colombia, pp. 83-129.

Bustamante de la Mora, A. (2002). La economía china: la visión de CESCE, Revista ICE China en el siglo XXI, 797, 63-69.

Casanova, L. (2006). Inversiones de China e India en el continente latinoamericano, INSEAD.

CEPAL (2010). Panorama de la inserción internacional de América Latina y del Caribe, Naciones Unidas, Santiago de Chile.

Cueva, Marcos. (2009). India y China en las relaciones económicas internacionales, Revista de relaciones internacionales de la UNAM, 103, 135-154. 
Delage, F. (2003). La política exterior china en la era de la globalización. Revista CIDOB D'AFERS INTERNACIONALS 63, 67-81.

Dirección Nacional de Planeación. (2012), Perfil comercial de Japón, [en línea] recuperado de http://www.tlc.gov.co/publicaciones.php?id=4818.

Fanjul, E. (2003). Relaciones comerciales: España en la China de la Reforma, Revista CIDOB D'AFERS INTERNACIONALS 63, 151-166.

Ferreiro, S. (2010). De los Andes a la Gran Muralla: 40 años de las relaciones entre Chile y China, Biblioteca nacional del Congreso de Chile, Valparaíso, Chile.

Grupo de estudio conjunto para un acuerdo de asociación económica entre Colombia y Japón. (2012). Reporte, [en línea] recuperado de http://www.tlc.gov.co/publicaciones. php?id=4818.

Leiteritz, R. J. (2012). China and Latin America: A Marriage Made in Heaven?, Revista Colombia Internacional, 75, 49-81.

Milanese, J. P. (2005). Colombia y Venezuela: motores y verdugos de la integración andina. Cuadernos de CLAEH (28), 91, serie 2, p. 32.

Ministerio de Comercio, Industria y Turismo. (2011). ABC del acuerdo comercial con Corea del Sur, [en línea] recuperado de http://www.tlc.gov.co/publicaciones.php?id=736.

Ministerio de Comercio, Industria y Turismo. (2012). Acuerdo de asociación económica entre Colombia y Japón: perfil económico y comercial, documento recuperado de http:// www.tlc.gov.co/publicaciones.php?id=3965.

Ministerio de Comercio, Industria y Turismo. (2013). Acuerdo de libre comercio entre la República de Colombia y la República de Corea: Perfil de Corea, [en línea] recuperado de http://www.tlc.gov.co/publicaciones.php?id=733.

Ministerio de Comercio, Industria y Turismo. (2014), Negociaciones en curso: Turquía y Japón, [en línea] recuperado de http://www.tlc.gov.co/publicaciones.php?id=5400.

Nacht, P. A. (2012). China y Argentina: "oportunidades y desafíos” o cristalización de una asociación independiente, Revista Relaciones Internacionales, 20, 107-128.

Orbes, V. E. (1998). Una propuesta de comercialización para las exportaciones menores y nuevas con destino japonés, Revista de economía de la Universidad del Rosario, 1, 145-160.

Palomares, G. J. (2011). Perspectiva constitucional de la Comunidad Andina: la jurisprudencia constitucional del Acuerdo de Cartagena, en Revista Iusta, No. 34, 135-155.

Posada, E. (2011). Relaciones Colombia-China: una agenda con futuro, en Barbosa, F.; Posada, E.; Serrano, E., La inserción de Colombia en el Asia Pacífico 2020: Colombia en el nuevo océano, Ministerio de Relaciones Exteriores y Fundación Universitaria Jorge Tadeo Lozano, Bogotá, Colombia. 
ProExport. (2010). Informe de exportaciones, importaciones, inversión extranjera y turismo, República de Corea, [en línea] recuperado de http://www.tlc.gov.co/publicaciones. php?id=736.

Ramírez, S. y Vieira, E. (2007). Colombia y el Perú en la Comunidad Andina: agenda de trabajo compartida, La inserción de Colombia en el sistema internacional cambianteGrupo Integración, en Policy Paper 29, recuperado de http://library.fes.de/pdf-files/ bueros/kolumbien/50487.pdf.

Reina, M. y García, C. (2008). Relaciones económicas entre Colombia y Japón: situación actual y alternativas para su fortalecimiento, [en línea] recuperado de http://www.tlc. gov.co/publicaciones.php?id=4818.

Reina, M. y Oviedo, S. (2013). Colombia y Asia: tratando de recuperar el tiempo perdido, Prepared for the conference "Reaching across the Pacific: Latin American and Asia in the new century”, [en línea] recuperado de http://www.wilsoncenter.org/sites/default/ files/DRAFT\%20PAPER\%20FOR\%20CONFERENCE_Reina.pdf.

Reina, M. y Salamanca, C. Forero, D., (2009). Análisis de factibilidad de un tratado de libre comercio entre Colombia y la República de Corea. Informe Final Fedesarrollo, [en línea] recuperado el 11.05.2015, de http://www.tlc.gov.co/publicaciones.php?id=736.

Rosales, O. y Kuwayama, M. (2007). América Latina al encuentro de China e India: perspectivas y desafíos en comercio e inversión, Revista de la CEPAL, 93, 85-108.

Shixue, J. (2006). Una mirada china a las relaciones con América Latina, [en línea] recuperado de http://dialnet.unirioja.es/servlet/articulo?codigo $=2380771$.

Wise, C. (2012). Tratados de libre comercio al estilo chino: los TLC Chile-China y PerúChina, University of Southern California, Centro de investigación de la Universidad del Pacífico, Perú.

Yaqing, Q. (2013). Desarrollo de la teoría de las relaciones internacionales en China, Revista Relaciones Internacionales, 22, 67-84. 